\title{
Racial disparities in medication use: imperatives for managed care pharmacy
}

\author{
Stephen J Kogut, PhD, MBA, RPh
}

\section{SUMMARY}

The COVID-19 pandemic and the social unrest pervading U.S. cities in response to the killings of George Floyd and other Black citizens at the hands of police are historically significant. These events exemplify dismaying truths about race and equality in the United States.

Racial health disparities are an inexcusable lesion on the U.S. health care system. Many health disparities involve medications, including antidepressants, anticoagulants, diabetes medications, drugs for dementia, and statins, to name a few. Managed care pharmacy has a role in perpetuating racial disparities in medication use. For example, pharmacy benefit designs are increasingly shifting costs of expensive medications to patients, creating affordability crises for lower income workers, who are disproportionally persons of color. In addition, the quest to maximize rebates serves to inflate list prices paid by the uninsured, among which Black and Hispanic people are overrepresented. While medication cost is a foremost barrier for many patients, other factors also propagate racial disparities in medication use. Even when cost sharing is minimal or zero, medication adherence rates have been documented to be lower among Blacks as compared with Whites. Deeper understandings are needed about how racial disparities in medication use are influenced by factors such as culture, provider bias, and patient trust in medical advice.

Managed care pharmacy can address racial disparities in medication use in several ways. First, it should be acknowledged that racial disparities in medication use are pervasive and must be resolved urgently. We must not believe that entrenched health system, societal, and political structures are impermeable to change. Second, the voices of community members and their advocates must be amplified. Coverage policies, program designs, and quality initiatives should be developed in consultation with those directly affected by racial disparities. Third, the industry should commit to dramatically reducing patient cost sharing for essential medication therapies. Federal and state efforts to limit annual out-of-pocket pharmacy spending should be supported, even though increased premiums may be an undesirable (yet more equitable) consequence. Finally, information about race should be incorporated into all internal and external reporting and quality improvement activities.

\author{
Author affiliation \\ Stephen J Kogut, PhD, MBA, RPh, \\ Department of Pharmacy Practice, \\ University of Rhode Island College \\ of Pharmacy, Kingston.
}

\section{AUTHOR CORRESPONDENCE: Stephen J Kogut, 401.874.5370, SKogut@URI.edu}

The COVID-19 pandemic and the social unrest pervading U.S. cities in response to the killings of George Floyd and other persons of color exemplify dismaying truths about race and equality in the United States. Rates of SARS-CoV-2 infection and hospitalizations have been higher among Blacks than for Whites, and Blacks have been more than twice as likely to die from COVID-19., ${ }^{1,2}$ These disparities mirror other health inequities among Blacks in the United States, including higher rates of being uninsured, ${ }^{3}$ higher infant and maternal mortality, 4,5 poorer health outcomes of chronic disease, ${ }^{6-8}$ and diminished life expectancy overall. ${ }^{9}$ These troubling realities undoubtedly add to the passion and anger expressed by the millions of protesters that have taken to our nation's streets. Their voices urge us all to reflect on our roles in perpetuating inequities, whether active or passive, and to commit in both spirit and action to advance change.

On June 18, 2020, AMCP issued a statement entitled "AMCP Stands Against Racial Injustice," stating that "we felt this letter was a crucial step 
for AMCP to take in the fight against racism and inequality." ${ }^{10}$ In contributing this unsolicited Viewpoints article, I intend to add to AMCP's statement by providing additional context and opinion and offering recommendations for action. I am a long-standing AMCP member and a former member of the JMCP Editorial Advisory Board (EAB). However, the views expressed in this article are my own and were developed without any consultation with AMCP leadership or EAB members. In addition, this article predominantly addresses disparities involving Black and Hispanic Americans, yet the issues and recommendations discussed extend to other groups who also experience disparities in medication use.

In 1966, Dr. Martin Luther King, Jr., in remarks associated with the Second National Convention of the Medical Committee for Human Rights, stated that "of all the forms of inequality, injustice in health care is the most shocking and inhumane."11 In the ensuing years the U.S. Department of Health and Human Services (HHS) has endeavored to respond. Racial disparities were detailed in a landmark report of the Secretary's Task Force on Black and Minority Health in $1985,{ }^{12}$ which led to the creation of the HHS Office of Minority Health (OMH). More recently, in 2011, HHS issued an Action Plan to Reduce Racial and Ethnic Health Disparities,$^{13}$ which included priorities, goals, and strategies to address "deeply rooted disparities that have defied major efforts toward progress for years." The Assistant Secretary for Planning and Evaluation published a progress report on this action plan in November $2015,{ }^{14}$ which described activities by federal agencies to address barriers and promote equity in health and health care. Also, in 2015, the $\mathrm{OMH}$ provided its biennial progress report on disparities to Congress, as required by the Affordable Care Act (ACA). The $\mathrm{OMH}$ under the Trump administration has not provided these required reports for 2017 or $2019 .{ }^{15}$ Also notable is the Institute of Medicine's 2003 report entitled "Unequal Treatment: Confronting Racial and Ethnic Disparities in Health Care, ${ }^{, 16}$ which included specific examples of racial disparities in prescription medication use. In addition, the Agency for Healthcare Research and Quality issues annual reports of health care quality and disparities that include comparisons across racial groups..$^{17}$ Despite these efforts, racial health disparities remain as an inexcusable lesion on the U.S. health care system.

Health disparities often involve medications, since prescription drug therapies are fundamental to basic health care. Managed care pharmacy promotes "a structured approach to financing and delivering covered health care benefits designed to provide affordable access to improve the quality of care in a cost-effective manner."18 Not explicitly stated in this definition, although assumedly implied, is the aim to provide affordable access and quality for all.
Is managed care pharmacy living up to this ideal? Racial disparities have been documented in the use of essential evidence-based drug therapies, including antidepressants, ${ }_{19}^{19}$ anticoagulants ${ }^{20}$ diabetes medications ${ }^{21}$ drugs for dementia, ${ }^{22}$ and statins,${ }^{23}$ to name a few. Racial or ethnic disparities in medication use have been associated with the failure to achieve therapeutic goals, increased rates of hospitalization, and decreased survival. ${ }^{24}$ Pharmacists have responded with initiatives to address disparities in medication use among underserved and vulnerable populations, more recently with heightened focus on the social determinants of health. ${ }^{25}$ However, medication cost remains a formidable barrier to closing the disparities gap in medication use between Blacks and Whites, among the uninsured, and for those having pharmacy coverage.

On average, Black and Hispanic people in the United States earn less than Whites. According to the U.S. Bureau of Labor Statistics, the median weekly full-time pay for White workers in 2018 was $\$ 916$, contrasted with $\$ 694$ for Blacks and $\$ 680$ for Hispanic workers. ${ }^{26}$ Hispanics and Blacks are also more likely to be paid poverty-level wages than Whites. ${ }^{27}$ Therefore, out-of-pocket prescription drug payments consume a higher percentage of the earnings of these groups, who may prioritize paying rent or obtaining food as a necessary trade-off. ${ }^{28-31}$ Patient cost sharing within the modern pharmacy benefit is often quite low. The average patient out-of-pocket contribution for a prescription medication in 2019 was $\$ 10.34,,^{32}$ which is less than half of the average price for a prescription medication nearly 30 years ago (\$22.06 in 1990), when more than half of prescriptions were paid for using cash. ${ }^{33}$ However, this comparison does not address prices paid by today's patients who lack health insurance, or the deviation in patient out-of-pocket spending associated with current pharmacy benefit designs.

Today's low average out-of-pocket prescription costs are driven by the increasing array of generic medications used in the management of prevalent chronic diseases. Examining patient out-of-pocket payments for brand name medications, and specialty medications in particular, reveals a different story. According to a report by the IQVIA Institute for Human Data Science on prescription drug spending and affordability, approximately $10 \%$ of brand name prescriptions in commercial and Medicare Part D plans required an out-of-pocket cost of $\$ 50$ or more in 2019. ${ }^{32}$ Moreover, the most frequent high-cost claims $(>\$ 125)$ were for medications indicated for diseases that disproportionally affect Blacks, including diabetes $,{ }^{34,35} \mathrm{HIV},{ }^{36}$ obesity ${ }^{37}$ respiratory disease, ${ }^{38,39}$ and stroke. ${ }^{40,41}$

The Medicare Part D benefit design also exposes patients to extremely high out-of-pocket costs. Yearly patient 
copayments for guideline-recommended medications for cancer can exceed $\$ 10,000$ under the Medicare Part D design. ${ }^{42}$ In the commercial sector, for benefits sponsored by large employers, more than half of designs with a tier for specialty drugs require coinsurance. ${ }^{43}$ Other trends in pharmacy benefit design include rising deductibles and, for high-deductible health plans, coinsurance within all tiers. ${ }^{43}$

Pharmacy benefit designs can pour salt on the wounds of those affected by disparities, parsing patients into the haves and have nots. Concerns about the effect of increased pharmacy cost sharing on medication access are not a new phenomenon ${ }^{44-46}$ yet the problem continues. In 2016, approximately $24 \%$ of insured low-income Americans reported skipping medications or doses due to cost. ${ }^{47}$ This exemplifies a shortcoming of unbridled capitalism in health care. ${ }^{48}$ While market forces can drive innovation and empower thriving systems for health care service delivery, perfectly competitive markets allocate goods and services according to the consumer's (patient's) willingness and ability to pay. As wealth and race are correlated,$^{49}$ pharmacy cost sharing is therefore not only an issue of patient affordability but also a matter of racial justice.

While the average per capita out-of-pocket spending for medications is not dramatically higher in the United States, the systems of other nations provide more protection against the highest levels of out-of-pocket spending. ${ }^{47}$ Many in the United States are in peril of financial ruin should they develop a disease that requires an expensive therapeutic. Indeed, more than half of U.S. bankruptcies have a medical origin, and most filers had health insurance. ${ }^{50}$ Disparities also exist in rates of accrued medical expenses, with Blacks being more than twice as likely than Whites to compile medical debt. ${ }^{51}$

\section{Racial Disparities in Medication Access Among the Uninsured}

The managed care pharmacy community must elevate its advocacy for the uninsured, who face substantial economic barriers in accessing medication. While racial disparities in health insurance coverage have improved since the passage of the $\mathrm{ACA},{ }^{52}$ these gains are threatened by the law's uncertain future. Among nonelderly adults, $14.4 \%$ of Blacks and $24.9 \%$ of Hispanic people nationally lacked health insurance in 2018, compared with only $8.6 \%$ of Whites. ${ }^{53}$ Uninsured individuals paid an average cash price of $\$ 43.67$ for a generic prescription and $\$ 105.74$ for a brand name prescription in 2019. ${ }^{32}$ Prices have been driven higher by the push for steeper rebates, placing upward pressure on drug list prices to yield greater discounts. ${ }^{54}$ Hence, rebate savings accrue to covered populations at the expense of those lacking coverage, among which approximately half are persons of color. ${ }^{55}$

The managed care pharmacy community should consider medication access for the uninsured to be a concern within its domain. Many of the uninsured were recently insured and may again have health coverage in the future. Data from the National Health Interview Survey for 2018 reveal that among the nonelderly uninsured, $21 \%$ had recently lost or changed jobs, while $13 \%$ recently lost eligibility for Medicaid. ${ }^{56}$ More must be done to aid those who are transitioning out of having prescription drug coverage. It might prove to be cost-effective to subsidize medication costs for the temporarily uninsured, rather than to later incur claims for disease complications. We should strive to overcome the system fragmentation that disincentivizes such an approach. Aside from the business case, from an ethical perspective, it is shameful that we allow so many lowincome Americans to be uninsured and without access to prescription drug coverage, while subsidizing prescription medication costs for all Part D beneficiaries, irrespective of their wealth. Therein lies the power of advocacy, which must now be leveraged to eliminate racial disparities in medication use among the insured and uninsured alike.

Health systems have been tasked with responding to the health-related needs of the community. Examples include Medicare's Accountable Health Communities Model and the ACA-mandated community health needs assessment reports that are required of nonprofit hospitals..$^{57,58}$ Moreover, there is growing recognition of the critical need to more fully and effectively engage community stakeholders to improve clinical care and enhance health system designs. In their 2018 article entitled "Transitioning from Learning Healthcare Systems to Learning Health Care Communities," Mullins et al. write that "the greatest disparities between low and high income patients as relates to differences in the degree of engagement with the health system and providers are seen in the USA." ${ }^{59}$ Accordingly, those in managed care pharmacy must increasingly engage community stakeholders in efforts to devise and implement strategies that reduce racial disparities in medication use. These efforts must be deliberate, prioritized, and sustained.

\section{It's Not Only About Cost}

While medication cost is a foremost barrier for many patients, other factors may propagate racial disparities in medication use. Even when cost sharing is minimal or zero, such as in Medicaid pharmacy programs, medication adherence rates have been documented to be lower among Blacks as compared with Whites. ${ }^{60-63}$ Deeper understanding is needed of how medication-related disparities are influenced 
by factors such as culture, provider bias, and trust in medical advice. Much can be learned by listening to members of communities affected by health disparities. Moreover, managed care pharmacy professionals must heighten collaborations with other health system professionals who serve those who are subjected to racial disparities. These workers include nurses, community health workers, clinical social workers, and community health center administrators, among others.

\section{What About the Drug Manufacturers?}

There is an elephant in the room yet to be addressed: medication prices. I am optimistic that managed care pharmacy will have a major role in transitioning drug payment models away from volume-driven rebates and towards value-based arrangements that recognize innovation and superior outcomes. Manufacturers should provide discounts or returned funds when the purported outcomes of a medication therapy are not fully realized, and these arrangements should include evaluating outcomes among racial groups. The data tracking required by value-based payment arrangements provides the impetus to more formally incorporate data on race, socioeconomic status, and social determinants of health when measuring key performance indicators. In addition, pharmacy and therapeutics committees should demand that dossiers for new drugs contain information about the effects of a new drug on health disparities. This might include incorporating details of known health disparities for the condition of interest and describing barriers to treatment access that may affect vulnerable groups.

There are also implications for pharmacoeconomic data. It is encouraging that cost-effectiveness analyses (CEAs) are increasingly used by managed care pharmacy decision makers in pricing negotiations. ${ }^{64}$ Yet these economic analyses typically consider a long time frame of therapy and assess cost from the perspective of the health system, not the patient. While CEAs for many specialty drugs purport cost-effectiveness according to predefined thresholds, many such medications require extremely high patient cost sharing. Cost-effectiveness is not a measure of affordability. Yet CEAs should not be eschewed as irrelevant to disparities; indeed, its application can optimize spending over the long run, enabling resources to be redirected to reduce patient cost sharing.

There is also a potential role for CEAs in evaluating the trade-offs in foregoing newer higher-priced medications in favor of "tried and true" lower-cost agents. Such studies would seem to be particularly salient for therapeutic areas where newer drugs are supplanting older evidence-based medications, such as in diabetes, mental health illnesses, and some types of cancer. A better understanding of these trade-offs would inform efforts to optimize program resources, while potentially substantially reducing patient out-of-pocket expenditures. This is not to suggest that some patients would be relegated to receive inferior medications. Rather, when making a difficult choice between purchasing an expensive new medication or obtaining food or paying rent, it would be helpful for patients to know how much potential health benefit would be foregone by selecting a next-best therapy that does not involve the same magnitude of financial strain.

\section{Suggestions for Action}

The managed care pharmacy community can help to eliminate racial disparities in medication use in several ways. First, it should be formally acknowledged that racial disparities in medication use are pervasive and must be resolved urgently. One must not believe that entrenched health system, societal, and political structures are impermeable to change.

Second, the voices of community members and their advocates must be amplified. Coverage policies, program designs, and quality initiatives should be developed in consultation with those directly affected by racial disparities.

Third, managed care pharmacy should commit to dramatically reduce patient cost sharing for essential medication therapies, for insured and uninsured populations. Federal and state efforts to limit annual out-of-pocket pharmacy spending should be supported, even though increased premiums may be an undesirable (yet more equitable) consequence.

Finally, information about race should be incorporated into all internal and external reporting and quality improvement activities. As the adage goes, "If you can't measure it, you can't improve it." ${ }^{65}$ Relatedly, managed care and pharmacy journal requirements should specify that researchers include race as a covariate whenever possible and consider yearly issues on the topic of racial disparities in medication use, particularly of studies involving interventions.

\section{Conclusions}

Former U.S. Representative and civil rights leader John Lewis said that "when you see something that is not right, not just, not fair, you have a moral obligation to say something, to do something." 66 The managed care pharmacy community can 
do its part by resolving to do more to eliminate racial disparities in medication use. Black Lives Matter.

Postscript: I hope that this essay will elicit responses from those who have been steadfastly working to address racial disparities in medication use. It is a failing of this article that I have not described the efforts of the many groups and individuals committed to this cause. We must all listen and learn from you.

\section{DISCLOSURES}

No funding was received for the development of this manuscript. Kogut is partially supported by Institutional Development Award Numbers U54GM115677 and P20GM125507 from the National Institute of General Medical Sciences of the National Institutes of Health, which funds Advance Clinical and Translational Research (Advance-CTR), and the RI Lifespan Center of Biomedical Research Excellence (COBRE) on Opioids and Overdose, respectively. The content is solely the responsibility of the author and does not necessarily represent the official views of the National Institutes of Health.

\section{ACKNOWLEDGMENTS}

The author acknowledges and profoundly thanks Jacquelyn Fede, PhD, MS (University of Rhode Island College of Health Sciences) and Anita Jacobson, PharmD (University of Rhode Island College of Pharmacy) for their thoughtful review and helpful suggestions which served to substantially improve this work.

\section{REFERENCES}

1. Stulpin C. Communities of color experience higher rates of COVID-19-related hospitalizations, deaths. Healio Infectious Disease News. May 15, 2020. Accessed August 2, 2020. https://www.healio.com/ news/infectious-disease/20200515/ communities-of-color-experience-higherrates-of-covid19related-hospitalizationsdeaths
2. Tai DBG, Shah A, Doubeni CA, Sia IG, Wieland ML. The disproportionate impact of COVID-19 on racial and ethnic minorities in the United States. Clin Infect Dis. Published online June 20, 2020. doi: 10.1093/cid/ciaa815

3. Buchmueller TC, Levy HG. The ACA's impact on racial and ethnic disparities in health insurance coverage and access to care. Health Aff (Millwood). 2020;39(3):395-402. doi: 10.1377/ hlthaff.2019.01394

4. Kirby RS. The US black-white infant mortality gap: marker of deep inequities. Am J Public Health. 2017;107(5):644-45.

5. Admon LK, Winkelman TNA, Zivin K, Terplan M, Mhyre JM, Dalton VK. Racial and ethnic disparities in the incidence of severe maternal morbidity in the United States, 2012-2015. Obstet Gynecol. 2018;132(5):1158-66.

6. Marron MM, Ives DG, Boudreau RM, Harris TB, Newman AB. Racial differences in cause-specific mortality between community-dwelling older black and white adults.

J Am Geriatr Soc. 2018;66(10):1980-86.

7. Probst JC, Zahnd WE, Hung P, Eberth JM, Crouch EL, Merrell MA. Rural-urban mortality disparities: variations across causes of death and race/ethnicity, 2013-2017. Am J Public Health. 2020;110(9):1325-27.

8. Davey Smith G, Neaton JD, Wentworth D, Stamler R, Stamler J. Mortality differences between black and white men in the USA: contribution of income and other risk factors among men screened for the MRFIT. MRFIT Research Group. Multiple Risk Factor Intervention Trial. Lancet. 1998;351(9107):934-39.

9. Bond MJ, Herman AA. Lagging life expectancy for black men: a public health imperative. Am J Public Health. 2016;106(7):1167-69.

10. Cantrell S, Schlaifer M. AMCP stands against racial injustice [letter]. June 18, 2020. Accessed August 6, 2020. https:// www.amcp.org/Resource-Center/blog/ amcp-stands-against-racial-injustice
11. Physicians for a National Health Program. Dr. Martin Luther King on health care injustice. Accessed August 2, 2020. https://pnhp.org/news/dr-martinluther-king-on-health-care-injustice

12. Heckler MM. Report of the Secretary's Task Force on Black and Minority Health. U.S. Department of Health and Human Services. 1985. Accessed August 3, 2020. https://minorityhealth.hhs.gov/assets/ pdf/checked/1/ANDERSON.pdf

13. U.S. Department of Health and Human Services. HHS action plan to reduce racial and ethnic health disparities. A nation free of disparities in health and health care. 2011. Accessed August 1, 2020. http://www. minorityhealth.hhs.gov/npa/files/Plans/ HHS/HHS Plan complete.pdf

14. HHS Office of the Assistant Secretary for Planning and Evaluation and Office of Minority Health. HHS action plan to reduce racial and ethnic health disparities implementation progress report. November 2015. Accessed August 4, 2020. https://aspe.hhs.gov/basic-report/hhsaction-plan-reduce-racial-and-ethnichealth-disparities-implementation-progress-report-2011-2014

15. Warren E, Markey E, Pressely A. Letter to HHS Secretary Alex M. Azar. July 14, 2020. Accessed August 5, 2020. http:// ct.symplicity.com/t/wrn/c167983feb6a233c8db11c27689bad9f/3769411739/ realurl=https:/www.warren.senate.gov/ imo/media/doc/2020.07.14\%20Letter\%20 to\%20HHS\%20re\%20missing\%20 racial\%20disparities\%20report.pdf

16. Institute of Medicine. Unequal Treatment: Confronting Racial and Ethnic Disparities in Health Care. National Academies Press; 2003.

17. Agency for Healthcare Research and Quality. 2018 National healthcare quality and disparities report. Page last reviewed April 2020. Accessed August 3, 2020. https://www.ahrq.gov/research/findings/nhqrdr/nhqdr18/index.html

18. AMCP. Managed care glossary. Accessed August 1, 2020. https://www. amcp.org/about/managed-care-pharmacy-101/managed-care-glossary 
19. Jung K, Lim D, Shi Y. Racial-ethnic disparities in use of antidepressants in private coverage: implications for the Affordable Care Act. Psychiatr Serv. 2014;65(9):1140-46.

20. Cruz-Flores S, Rabinstein A, Biller J, et al. Racial-ethnic disparities in stroke care: the American experience: a statement for healthcare professionals from the American Heart Association/ American Stroke Association. Stroke. 2011;42(7):2091-116.

21. Trinacty CM, Adams AS, Soumerai SB, et al. Racial differences in long-term adherence to oral antidiabetic drug therapy: a longitudinal cohort study. BMC Health Serv Res. 2009;9:24.

22. Mehta KM, Yin M, Resendez C, Yaffe K. Ethnic differences in acetylcholinesterase inhibitor use for Alzheimer disease. Neurology. 2005;65(1):159-62.

23. Karpinski SA, Look KA, Vanness DJ. Factors associated with county-level variation in the prescription of statins. J Manag Care Spec Pharm. 2019;25(12):135865. doi: 10.18553/jmcp.2019.25.12.1358

24. Hall-Lipsy EA, Chisholm-Burns MA. Pharmacotherapeutic disparities: racial, ethnic, and sex variations in medication treatment. Am J Health Syst Pharm. 2010;67(6):462-68.

25. Pestka DL, Espersen C, Sorge LA, Funk KA. Incorporating social determinants of health into comprehensive medication management: insights from the field. J Am Coll Clin Pharm. 2020;3(6):1038-47.

26. U.S Bureau of Labor Statistics. Labor force characteristics by race and ethnicity, 2018. BLS Reports. Report 1082. October 2019. Accessed August 1, 2020. https://www.bls.gov/opub/reports/raceand-ethnicity/2018/home.htm

27. Cooper D. Workers of color are far more likely to be paid poverty-level wages than white workers. Working Economics Blog. June 21, 2018. Accessed August 1 , 2020. https://www.epi.org/blog/ workers-of-color-are-far-more-likely-tobe-paid-poverty-level-wages-than-whiteworkers/
28. Herman D, Afulani P, Coleman-Jensen A, Harrison GG. Food insecurity and costrelated medication underuse among nonelderly adults in a nationally representative sample. Am J Public Health. 2015;105(10):e48-e59.

29. Kushel MB, Gupta R, Gee L, Haas JS. Housing instability and food insecurity as barriers to health care among lowincome Americans. J Gen Intern Med. 2006;21(1):71-77.

30. Surratt HL, O'Grady CL, Levi-Minzi MA, Kurtz SP. Medication adherence challenges among HIV positive substance abusers: the role of food and housing insecurity. AIDS Care. 2015;27(3):307-14.

31. Nguyen NH, Khera R, Ohno-Machado L, Sandborn WJ, Singh S. Estimates of the prevalence and effects of food insecurity and social support on financial toxicity in and healthcare use by patients with inflammatory bowel diseases. Clin Gastroenterol Hepatol. Published online June 8, 2020. doi: 10.1016/j. cgh.2020.05.056

32. INQVIA Institute for Human Data Science. Medicine spending and affordability in the United States: understanding patients' costs for medicines. August 2020. Accessed August 1, 2020. https:// www.iqvia.com/insights/the-iqvia-institute/reports/medicine-spending-andaffordability-in-the-us

33. Kaiser Family Foundation. Prescription drug trends: a chartbook update.

November 2001. Accessed August 5, 2020. http://files.kff.org/attachment/reportprescription-drug-trends-a-chartbookupdate

34. Harris MI. Noninsulin-dependent diabetes mellitus in black and white Americans. Diabetes Metab Rev. 1990;6(2):71-90.

35. Clements JM, West BT, Yaker Z, et al. Disparities in diabetes-related multiple chronic conditions and mortality: the influence of race. Diabetes Res Clin Pract. 2020;159:107984.
36. Millett GA, Peterson JL, Flores SA, et al. Comparisons of disparities and risks of HIV infection in black and other men who have sex with men in Canada, UK, and USA: a meta-analysis. Lancet. 2012;380(9839):341-48.

37. Centers for Disease Control and Prevention. Differences in prevalence of obesity among black, white, and Hispanic adults - United States, 20062008. MMWR Morb Mortal Wkly Rep. 2009;58(27):740-44.

38. Forno E, Celedón JC. Health disparities in asthma. Am J Respir Crit Care Med. 2012;185(10):1033-35.

39. Ejike CO, Dransfield MT, Hansel NN, et al. Chronic obstructive pulmonary disease in America's black population. Am J Respir Crit Care Med. 2019;200(4):423-30.

40. Howard G, Moy CS, Howard VJ, et al. Where to focus efforts to reduce the black-white disparity in stroke mortality: incidence versus case fatality? Stroke. 2016;47(7):1893-98.

41. Qian F, Fonarow GC, Smith EE, et al. Racial and ethnic differences in outcomes in older patients with acute ischemic stroke. Circ Cardiovasc Qual Outcomes. 2013;6(3):284-92.

42. Cubanski J, Koma W, Neuman T. The out-of-pocket cost burden for specialty drugs in Medicare Part D in 2019. Kaiser Family Foundation. February 1, 2019. Accessed August 5, 2020. https://www. kff.org/medicare/issue-brief/the-outof-pocket-cost-burden-for-specialtydrugs-in-medicare-part-d-in-2019/?utm campaign=KFF-2019-January-MedicarePart-D-Enrollees-Costs-Specialty-Drugs

43. Kaiser Family Foundation. 2019 Employer health benefits survey. September 25, 2019. Accessed August 5, 2020. https://www.kff.org/report-section/ehbs-2019-section-9-prescriptiondrug-benefits/

44. Goldman DP, Joyce GF, Zheng Y. Prescription drug cost sharing: associations with medication and medical utilization and spending and health. JAMA. 2007;298(1):61-69. 
45. Gleason PP, Starner CI, Gunderson BW, Schafer JA, Sarran HS. Association of prescription abandonment with cost share for high-cost specialty pharmacy medications. J Manag Care Pharm. 2009;15(8):648-658. doi:10.18553/ jmcp.2009.15.8.648

46. Doshi JA, Li P, Ladage VP, Pettit AR, Taylor EA. Impact of cost sharing on specialty drug utilization and outcomes: a review of the evidence and future directions. Am J Manag Care. 2016;22(3):188-97.

47. Sarnak DO, Squires D, Bishop S. Paying for prescription drugs around the world: why is the U.S. an outlier? The Commonwealth Fund. October 2017 Accessed August 3, 2020. https://www. commonwealthfund.org/publications/ issue-briefs/2017/oct/paying-prescription-drugs-around-world-why-us-outlier

48. McKee M, Stuckler D. The crisis of capitalism and the marketisation of health care: the implications for public health professionals. J Public Health Res. 2012;1(3):236-39.

49. Pew Research Center. On views of race and inequality, blacks and whites are worlds apart. June 27, 2016. Accessed August 2, 2020. https://www.pewsocialtrends.org/2016/06/27/on-views-ofrace-and-inequality-blacks-and-whitesare-worlds-apart/

50. Himmelstein DU, Thorne D, Warren E, Woolhandler S. Medical bankruptcy in the United States, 2007: results of a national study. Am J Med. 2009;122(8):741-46.

51. Wiltshire JC, Elder K, Kiefe C, Allison JJ. Medical debt and related financial consequences among older African American and white adults. Am J Public Health. 2016;106(6):1086-91.

52. Buchmueller TC, Levy HG. The ACA's impact on racial and ethnic disparities in health insurance coverage and access to care. Health Aff (Millwood). 2020;39(3):395-402.
53. Baumgartner JC, Collins SR, Radley DC, Hayes SL. How the Affordable Care Act has narrowed racial and ethnic disparities in access to health care. The Commonwealth Fund. January 16, 2020. Accessed August 2, 2020. https:// www.commonwealthfund.org/publications/2020/jan/how-ACA-narrowedracial-ethnic-disparities-access

54. Sood N, Ribero, Ryan M, Van Nuys K. The association between drug rebates and list prices. Leonard D. Schaeffer Center for Health Policy \& Economics. White paper. February 11, 2020. Accessed August 2, 2020. https://healthpolicy.usc.edu/ research/the-association-between-drugrebates-and-list-prices/

55. Young CL. There are clear, racebased inequalities in health insurance and health outcomes. USC-Brookings Schaeffer on Health Policy. February 19, 2020. Accessed August 5, 2020. https:// www.brookings.edu/blog/usc-brookingsschaeffer-on-health-policy/2020/02/19/ there-are-clear-race-based-inequalitiesin-health-insurance-and-health-outcomes/

56. Tolbert J, Orgera K, Singer S, Damico A. Key facts about the uninsured population. Kaiser Family Foundation. December 13, 2019. Accessed August 2, 2020. https:// www.kff.org/uninsured/issue-brief/keyfacts-about-the-uninsured-population/

57. Chaiyachati KH, Grande DT, Aysola J. Health systems tackling social determinants of health: promises, pitfalls, and opportunities of current policies. Am J Manag Care. 2016;22(11):e393-e394.

58. Pennel CL, McLeroy KR, Burdine JN, Matarrita-Cascante D. Nonprofit hospitals' approach to community health needs assessment. Am J Public Health. 2015;105(3):e103-e113.
59. Mullins CD, Wingate LT, Edwards HA, Tofade T, Wutoh A. Transitioning from learning healthcare systems to learning health care communities. J Comp Eff Res. 2018;7(6):603-14.

60. Shenolikar RA, Balkrishnan R, Camacho FT, Whitmire JT, Anderson RT. Race and medication adherence in Medicaid enrollees with type-2 diabetes. J Natl Med Assoc. 2006;98(7):1071-77.

61. Ji X, Druss BG, Lally C, Cummings JR. Racial-ethnic differences in patterns of discontinuous medication treatment among Medicaid-insured youths with ADHD. Psychiatr Serv. 2018;69(3):322-31.

62. Youn B, Shireman TI, Lee Y, Galárraga O, Wilson IB. Trends in medication adherence in HIV patients in the U.S., 2001 to 2012: an observational cohort study. J Int AIDS Soc. 2019;22(8):e25382.

63. Kyanko KA, Franklin RH, Angell SY. Adherence to chronic disease medications among New York City Medicaid participants. J Urban Health. 2013;90(2):323-28.

64. ICON. Payer reliance on ICER assessments and perceptions on value based Pricing. White paper. November 15, 2019. Accessed August 5, 2020. https://www. iconplc.com/insights/blog/2019/11/15/ payers-report-that-icer-analyses-increasingly-guide-us-price-negotiations /

65. Philippart M. Management maxim was Lord Kelvin's [letter]. Financial Times. Nov. 28, 2018. Accessed August 5, 2020. https://www.ft.com/content/c999cbaef1a5-11e8-9623-d7f9881e729f

66. Snell K, Cornish A. Rep. John Lewis, a force in the civil rights movement, dead at 80. WGBH News. July 17, 2020. Accessed August 7, 2020. https://www.wgbh.org/ news/national-news/2020/07/18/repjohn-lewis-a-force-in-the-civil-rightsmovement-dead-at-80 